\title{
The influence of work-family experiences during deployment on organizational outcomes
}

\author{
Helen Pluut and Manon Andres
}

\begin{abstract}
This work examines tensions in the military-employee-family triad and how it influences employees' and partners' attitudes toward the organization. Survey data from Navy personnel and their partners were collected while they were geographically separated due to deployment. Results show that tensions between work and family perceived by employees and their partners affect organizational outcomes, via distinct mechanisms. Among deployed Navy personnel, work-to-family conflict positively predicts turnover intentions via negative attitudes toward the Navy. Family-to-work conflict predicts turnover intentions via cognitive failures at work and the associated reduced job satisfaction. Work-family-specific support received from team members, on-board the ship, is shown to be an important mechanism in reducing tensions between work and family and their detrimental effects. Among the stay-at-home partners, views that military job demands interfere with their family life are not uncommon, and such views are negatively associated with partners' attitudes towards the Navy. Satisfaction with support organized by the Navy is positively associated with all attitudes toward the Navy and buffers the detrimental effects of perceived work-family conflict on partners' identification with the Navy.
\end{abstract}




\section{Introduction}

Although work-family conflict is a universal phenomenon (Allen, French, Dumani, and Shockley, 2015), the specific dynamics of work-family issues are likely to be shaped by national culture (Powell, Francesco, and Ling, 2009) and may even reflect the specific challenges of the industry or sector. The military poses a unique set of demands on employees and their families, including frequent and long-term family separations due to training, military deployments, and postings, which increases the likelihood of work-family conflict (Adams, Jex, and Cunningham, 2006). The military and the family are described as greedy institutions (Segal, 1986) and have always been connected. Military employees are embedded in both institutions; they negotiate terms and conditions of work with the military and they negotiate the boundaries between work and non-work with their family. Tensions in the military-employee-family triad (see the framework put forward in this volume and described in more detail in Chapter 1) are assumed to affect all parties involved, yet here we are particularly interested in how work-family tensions affect organizational outcomes. That is, conflict between the military and the family may be greater today than in the past (De Angelis and Segal, 2015) and this creates challenges for the military in attracting and retaining personnel.

The notion of family-relatedness of work decisions (Greenhaus and Powell, 2012) implies that partners may have considerable influence on an employee's work decisions, such as reenlisting with the Navy (see also Huffman, Casper, and Payne, 2013). Not surprisingly, then, the military — as a greedy institution — wants both service members and their families to be committed to the institution (Bourg and Segal, 1999). Despite a growing body of research on military families, little is known about family members' attitudes toward the military. This chapter is guided by the following overall research question: how do tensions between work and family affect employees' and their families' attitudes toward the military? We aim to answer this research question through a study among deployed Navy personnel and their stay-at-home partners. 


\section{Theoretical background}

\section{Work-to-family conflict and organizational outcomes}

By its very nature, military deployment entails a form of work-to-family conflict because individuals are separated from their families and opportunities for communication are limited (Andres, Moelker, and Soeters, 2012). Evidently, this puts considerable strain on Navy personnel and their families. We propose that Navy personnel who experience work-to-family conflict will be less likely to reenlist and stay with the Navy, and we focus on overall satisfaction and organizational identification as attitudes that may explain why Navy personnel would decide to stay with or leave the organization.

First, it is likely that people attribute blame to the domain that is the source of conflict and subsequently will develop negative attitudes toward the domain that causes the conflict. This notion has been referred to as the source attribution perspective (Shockley and Singla, 2011). In the case of work interfering with family, it might very well be, as Shockley and Singla (2011: 864) noted, that "an individual is likely to ... be dissatisfied with the work because it caused the conflict to occur, rather than the family role, which is merely a victim of the interference." Thus, we expect that those service members who experience high work-to-family conflict will be less satisfied with the Navy and will identify less strongly with the Navy compared to those who experience low workto-family conflict.

Second, negative attitudes toward the Navy will reduce the likelihood that a service member wants to reenlist. Overall satisfaction with the job has consistently been found to correlate with both turnover intentions and actual employee turnover (Cotton and Tuttle, 1986; Griffeth, Hom, and Gaertner, 2000; Tett and Meyer, 1993; see Kelly et al., 2001, for a study among Navy mothers). Moreover, organizational identification has been found to predict lower-turnover intentions (Van Dick et al., 2004). Thus, we predict that satisfaction and identification with the Navy are negatively associated with turnover intentions among Navy personnel. The preceding arguments imply that higher turnover intentions among personnel who experience high rather than low levels of work-to-family conflict can be explained (are mediated) by negative attitudes toward the Navy. 
Hypothesis 1: Work-to-family conflict reported by Navy personnel positively predicts turnover intentions via reduced satisfaction and identification with the Navy.

\section{Family-to-work conflict and organizational outcomes}

It is not uncommon during deployment for family concerns to intrude on the workplace. We propose that family-to-work conflict experienced during a military deployment may affect the work quality of Navy personnel. Family-to-work conflict makes it more likely for people to experience off-task thoughts and engage in unintended behaviors (Demerouti, Taris, and Bakker, 2007). It can lead to employees failing to recall work procedures, not remembering whether they turned off work equipment, not noticing postings, or not fully listening to instructions and getting distracted easily. These are examples of what have been referred to as cognitive failures (Broadbent, Cooper, FitzGerald, and Parkes, 1982; Wallace and Chen, 2005). In one of the few studies focusing specifically on workplace cognitive failures, Lapierre, Hammer, Truxillo, and Murphy (2012) observed that family interference with work was positively related to increased cognitive failures at work.

We posit that Navy personnel who experience high levels of family-to-work conflict during deployment might be more prone to experiencing cognitive failures at work. Thinking or worrying about what happens at home may limit the attention they can devote to their work, setting them up for mistakes. Importantly, cognitive failures may make people frustrated and the work experience less satisfactory because people will perceive they are unsuccessful in their goal pursuit (Lent and Brown, 2006). Metaanalyses indicate that job satisfaction is associated with lower turnover intentions (see Cotton and Tuttle, 1986; Griffeth, Hom, and Gaertner, 2000; Tett and Meyer, 1993). Hence, we predict that family-to-work conflict is associated with higher turnover intentions because those individuals who experience more family-to-work conflict show higher levels of cognitive failures at work and therefore have lower job satisfaction.

Hypothesis 2: Family-to-work conflict reported by Navy personnel predicts turnover intentions via cognitive failures during deployment and the associated reduced job satisfaction. 


\section{The role of support in relation to work-to-family conflict}

Social support is a much-emphasized concept in the work-family literature (Kossek, Pichler, Bodner, and Hammer, 2011; Van Daalen, Willemsen, and Sanders, 2006). In the current study, we focus on the team as a source of workplace social support during deployment because Navy personnel are highly dependent on team members with whom they work and live together on the ship. Importantly, we focus on social support that is specifically targeted at facilitating the employee's ability to manage work-family issues. Kossek and colleagues (2011) found that work-family-specific forms of supervisor and organizational support were more strongly related to work-family conflict than general forms of support. Here, we focus on Navy personnel's perceptions of the degree to which their team is seen as family supportive and we study this type of support in relation to both work-to-family conflict and family-to-work conflict.

We propose that the experience of being part of a team that offers work-family support may buffer the relationship between work-to-family conflict and negative attitudes toward the Navy. The availability of work-family support in the workplace is reflective of a family-friendly organizational culture (Premeaux, Adkins, and Mossholder, 2007). In a similar way to how supportive supervisors will lead an employee to perceive the organization as supportive (Shanock and Eisenberger, 2006; Kossek, Pichler, Bodner, and Hammer, 2011), we believe that a work-family supportive team climate is related to perceptions of organizational support. This should help Navy personnel to take a more positive outlook on the Navy despite the experience of workto-family conflict. Thus, work-to-family conflict may lead to negative attitudes to the Navy through a process of placing blame and retaliation, yet if the individual feels supported in the work-family interface, this may reduce reactivity to negative workfamily experiences.

Hypothesis 3: Work-family team support buffers the detrimental effects of workto-family conflict on satisfaction and identification with the Navy.

\section{The role of support in relation to family-to-work conflict}

When individuals feel supported at work, in that they can share their concerns about their family and get advice on family matters, it is easier for them to leave their troubles 
behind and psychologically detach from home. A family-supportive team climate allows for the discussion of any problems that may otherwise form a distraction while working. In addition to preventing cognitive interference, showing empathy to a person with family concerns may reduce emotional strain that may interfere with work performance (Beauregard, 2006). Thus, we hypothesize that family is less likely to interfere with work if employees receive more work-family team support.

\section{Hypothesis 4: Work-family team support diminishes levels of family-to-work conflict.}

\section{The partner's perspective}

We propose that partners' attitudes toward the Navy are highly influenced by the degree to which they feel that the work of the service member interferes with their family life. The job of Navy personnel involves frequent and long-term family separations and a person may feel that their partner's job in the Navy is incompatible with their family life. In line with the source attribution perspective, they may in turn ascribe more negative cognitions to their partner's employer. Specifically, we expect that higher levels of work-to-family conflict (in the eyes of the partner) reduce the level of how satisfied the partner is with the Navy and the degree of identification with the Navy. Moreover, we expect that higher levels of work-to-family conflict make it difficult for the partner to accept job-induced separations as part of their life. Finally, work-tofamily conflict will lead an individual to form a more negative opinion on whether the Navy is a good career choice for their partner. Thus, similar to our argument for Navy personnel, we hypothesize that higher levels of tensions in the work-family relationship negatively affect partners' attitudes toward the organization.

\section{Hypothesis 5: Partners' views of work-to-family conflict are negatively} associated with their attitudes toward the Navy.

A person can draw support from different sources during their partner's assignment abroad - for instance, family and friends-yet the Navy also organizes support for families. In a similar way to how social support available on the ship may reduce reactivity to work-family issues in deployed Navy personnel, support provided to partners may influence the relationship between work-to-family conflict and their 
attitudes toward the Navy. If partners are satisfied with the support organized by the Navy, it stands to reason-on the basis of social exchange theory (see Peeters, Ten Brummelhuis, and Van Steenbergen, 2013) - that they want to reciprocate the efforts made by the Navy by evaluating this organization more positively, in spite of the fact that they attribute any work-family tensions to their partner's work for the Navy. Specifically, we expect that perceived organizational support moderates the relationship between partners' views of work-to-family conflict on the one hand and their satisfaction and identification with the Navy as well as their acceptance of separation and evaluation of a Navy career on the other hand.

Hypothesis 6: Perceived organizational support buffers the detrimental effects of partners' views of work-to-family conflict on their attitudes toward the Navy.

\section{Method}

\section{Sample and procedure}

Data were collected among deployed military personnel of the Dutch Navy and their partners at home. It was communicated that the research focused on the relation between work and family and aimed at investigating the experiences of Navy personnel and the home front. The survey data stem from multiple ships that participated in the study. The researchers brought the surveys on-board to the commander in chief before a ship would leave on a mission. The commander in chief distributed the surveys among the military personnel one month before returning home; an accompanying letter was enclosed, which explained the purpose of the study and emphasized confidentiality. The completed surveys were returned anonymously in a box on-board the ship, which was handed over to the researchers immediately after the ship returned from its mission. At the same time as the surveys were distributed among military personnel on-board, personnel's partners received a survey at their home addresses. Our sample consists of 351 Navy personnel (a response rate of 46 percent), of which 89 were not in a committed relationship. A total of 125 partners completed the survey (a response rate of 57 percent). We could match survey records for 86 military couples.

The Navy personnel were predominantly male ( 89 percent) and, on average, they were 31 years old $(S D=9.03)$, ranging from 19 to 53 . The majority of them ( 75 percent) 
were in a committed relationship, 25 percent were not (and defined other persons than a partner as their families); 40 percent had children. Almost all partners were female (93 percent) and they were on average 35 years old $(S D=8.78)$, varying from 19 to 54 . Little more than half of them (58 percent) had children. A large majority of the partners (87 percent) had paid employment, of which 26 percent also worked or had worked within the Ministry of Defense.

\section{Employee survey}

With few exceptions, the surveys contained validated scales, which were translated from English as the survey was administered in Dutch.

Work-to-family conflict. We used the five-item Work-Family Conflict Scale developed by Netemeyer, Boles, and McMurrian (1996) to assess the extent to which the work of Navy personnel interferes with family in general (e.g., "The demands of my work interfere with my home and family life"). Responses were given on a fivepoint Likert Scale ranging from 1 (strongly disagree) to 5 (strongly agree). The Cronbach's alpha was 0.88 .

Family-to-work conflict. Five items from the SWING (Geurts et al., 2005) were adapted to assess the extent to which family interfered with work during the current mission of Navy personnel (e.g., "I do not feel like working because I miss my partner/family"). Responses were given on a five-point Likert Scale ranging from 1 (strongly disagree) to 5 (strongly agree) and the Cronbach's alpha was 0.86 .

Satisfaction with Navy. We used two items to assess how satisfied Navy personnel were with their job at the Navy: "All things considered, how satisfied are you with the Navy?" and "How satisfied are you with the family life you can have when employed at the Navy?" Answers were given on a scale from 1 (very dissatisfied) to 5 (very satisfied). The Spearman-Brown coefficient (see Eisinga, Te Grotenhuis, and Pelzer, 2013) for this two-item scale was 0.60 .

Identification with Navy. We used a single-item graphic scale developed by Shamir and Kark (2004) for the measurement of organizational identification. Respondents were presented with seven pairs of circles with varying degrees of overlap, from 1 (no 
overlap) to 7 (complete overlap). One circle represented the respondent and the other the Navy. Respondents were asked to choose the pair of circles that best represented their current relationship with the Navy. The higher the overlap between circles, the higher the identification with the Navy.

Cognitive failures. We used the eight-item Cognitive Failures Questionnaire-forothers by Broadbent, Cooper, FitzGerald, and Parkes (1982) to assess Navy personnel's level of cognitive exhaustion during deployment. We adapted the items to reflect selfreported failures and also shortened the items. Respondents were asked how they had felt during their current deployment (e.g., "I found it difficult to concentrate on anything"). Answers were given on a five-point Likert Scale ranging from 1 (strongly disagree) to 5 (strongly agree). The Cronbach's alpha for this scale was 0.94.

Job satisfaction. Navy personnel's job satisfaction was assessed with five items from the Brayfield and Rothe (1951) measure (e.g., "Most days I am enthusiastic about my work). Responses were given on a five-point Likert Scale ranging from 1 (strongly disagree) to 5 (strongly agree). The Cronbach's alpha was 0.85 .

Turnover intentions. We used three often-used items on turnover intention from prior research among military families (e.g., Andres, Moelker, and Soeters, 2012): "I often think about leaving the Navy," "I will probably look for a new job in the next year," and "I would like to stay in this organization until I retire." Ratings were obtained on a five-point Likert Scale ranging from 1 (strongly disagree) to 5 (strongly agree). The Cronbach's alpha was 0.80 .

Work-family-specific team support. We used the three items from Kossek, Colquitt, and Noe (2001) to assess a family-supportive work climate. We adapted these items to fit a team setting (e.g., "In our team, it is generally accepted that people share concerns about their family"). Answers were given on a five-point Likert Scale ranging from 1 (strongly disagree) to 5 (strongly agree). The Cronbach's alpha was 0.82 .

\section{Partner survey}

Work-to-family conflict. We administered the same scale to partners at home as we did to employees, with slight adjustments, to assess partners' perceptions of how the naval 
job interferes with their family life (e.g., "The demands of my partner's job interfere with our home and family life"). The Cronbach's alpha was 0.85 .

Satisfaction with the Navy. Similar to Navy personnel, but with slight adaptions, we assessed partners' satisfaction with the Navy: "All things considered, how satisfied are you with the Navy?" and "How satisfied are you with the family life you can have when your partner is employed at the Navy?" The Spearman-Brown coefficient for this twoitem scale in the partner sample was 0.58 .

Acceptance of separation. We used four self-constructed items to assess the extent to which partners were able to accept the fact that their partner is often away from home because of the naval job (e.g., "I accept that sailing is part of my partner's work"). Answers were recorded on a five-point Likert Scale ranging from 1 (strongly disagree) to 5 (strongly agree) and the Cronbach's alpha was 0.84 .

Opinion on the Navy as a career choice. A self-constructed one-item measure was used to assess partners' opinion about their partner working at the Navy. Answer categories ranged from $1=I$ consider the Navy a good career choice to $3=I$ do not mind to $5=$ I want my partner to leave as quickly as possible.

Perceived organizational support. We developed two items that asked partners to what extent they were satisfied with the support made available to them during the absence of their partner. One item focused on support organized by the Navy, the other on support organized by home front groups. Answers were given on a five-point Likert Scale and the Spearman-Brown coefficient for this two-item scale was 0.85 .

\section{Results}

\section{Analyses}

We examined the data among Navy personnel and partners separately. Descriptive statistics (i.e., means, standard deviations, and intercorrelations) are presented in Tables 9.1 and 9.2 . 
Table 9.1

Descriptive statistics, Navy personnel

\begin{tabular}{|c|c|c|c|c|c|c|c|c|c|c|}
\hline & Variable & Mean & $S D$ & 1 & 2 & 3 & 4 & 5 & 6 & 7 \\
\hline 1 & Work-to-family conflict & 3.04 & 0.84 & 1 & & & & & & \\
\hline 2 & Family-to-work conflict & 2.55 & 0.76 & $.43^{* * *}$ & 1 & & & & & \\
\hline 3 & WF-specific team support & 3.65 & 0.62 & $-.13^{*}$ & $-.14^{*}$ & 1 & & & & \\
\hline 4 & Cognitive failures & 2.04 & 0.74 & $.17^{* *}$ & $.51^{* * *}$ & $-.24^{* * *}$ & 1 & & & \\
\hline 5 & Job satisfaction & 3.70 & 0.61 & $-.31^{* * *}$ & $-.40^{* * *}$ & $.24^{* * *}$ & $-.48^{* * *}$ & 1 & & \\
\hline 6 & Satisfaction with Navy & 3.17 & 0.74 & $-.49^{* * *}$ & $-.39^{* * *}$ & $.16^{* *}$ & $-.29^{* * *}$ & $.58^{* * *}$ & 1 & \\
\hline 7 & Identification with Navy & 4.15 & 1.40 & $-.23^{* * *}$ & $-.29^{* * *}$ & $.17^{* *}$ & $-.26^{* * *}$ & $.47^{* * * *}$ & $.52^{* * *}$ & 1 \\
\hline 8 & Turnover intentions & 2.61 & 0.96 & $.25^{* * *}$ & $.24^{* * * *}$ & -.10 & $.26^{* * * *}$ & $-.51^{* * *}$ & $-.58^{* * * *}$ & $-.57^{* * * *}$ \\
\hline
\end{tabular}

Note. $\mathrm{WF}=$ work-family.

$* p<.05 . * * p<.01 . * * * p<.001$.

Table 9.2

Descriptive statistics, partners

\begin{tabular}{|c|c|c|c|c|c|c|c|c|}
\hline & Variable & Mean & $S D$ & 1 & 2 & 3 & 4 & 5 \\
\hline 1 & Work-to-family conflict & 3.21 & 0.85 & 1 & & & & \\
\hline 2 & Support by Navy & 3.61 & 0.80 & $-.30^{* *}$ & 1 & & & \\
\hline 3 & Satisfaction with Navy & 3.60 & 0.68 & $-.54^{* * *}$ & $.46^{* * *}$ & 1 & & \\
\hline 4 & Identification with Navy & 3.60 & 1.49 & $-.31^{* * *}$ & $.32^{* * *}$ & $.44^{* * *}$ & 1 & \\
\hline 5 & Opinion on Navy as career & 2.01 & 0.96 & $-.40^{* * *}$ & $-.34^{* * * *}$ & $-.37^{* * *}$ & $-.34^{* * *}$ & 1 \\
\hline 6 & Acceptance of separation & 3.99 & 0.78 & $-.46^{* * *}$ & $.34^{* * *}$ & $.52^{* * *}$ & $.32^{* * *}$ & $-.39^{* * *}$ \\
\hline
\end{tabular}


First, we used data only from the Navy personnel sample $(\mathrm{N}=351)$ to test our hypothesized model in Figure 9.1. We used path analysis in AMOS version 22 to test the interrelations in the hypothesized model simultaneously. We specified covariances between the exogenous variables in our model and further allowed the error terms of the variables "satisfaction with the Navy" and "identification with the Navy" to covary as these constructs may have common sources of unexplained variance. Second, we used data from the partner sample $(\mathrm{N}=125)$ to test our hypothesized model in Figure 9.2. For testing interactions, we centered the predictor variables prior to computing the product term.

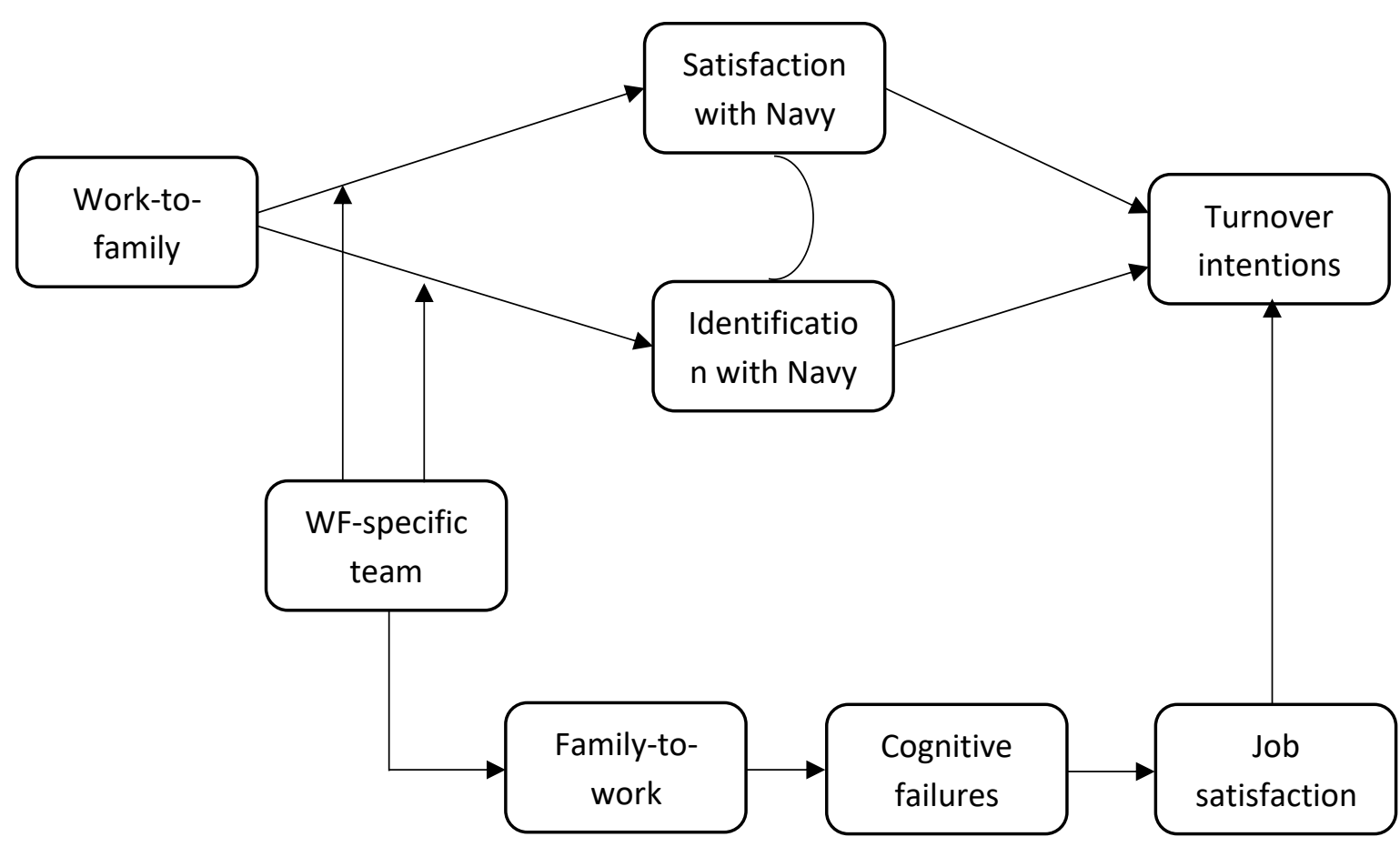

Figure 9.1

Hypothesized model for Navy personnel 


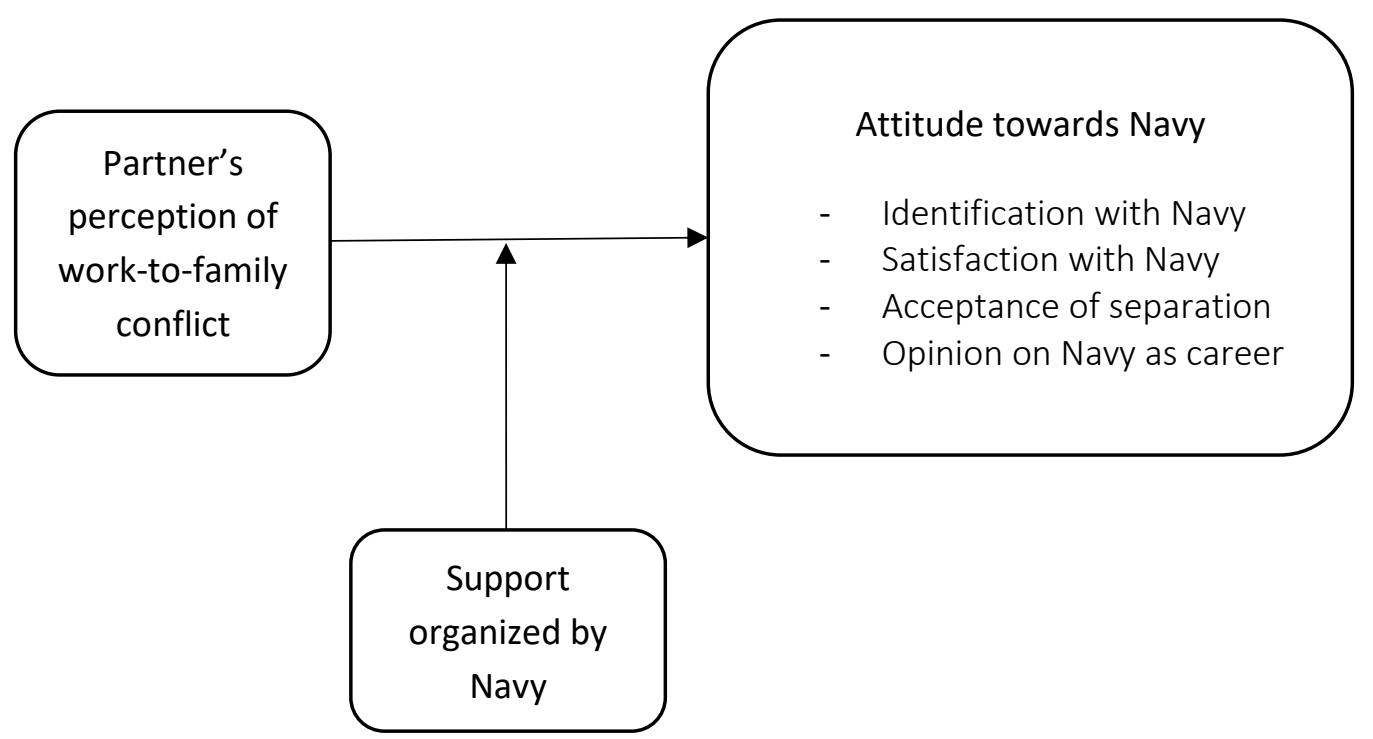

Figure 9.2

Hypothesized model for partners of Navy personnel

To assess congruence with the data, we report the chi-square value $\left(\chi^{2}\right)$ and both incremental and absolute-fit indices. The model depicted in Figure 9.1 does not show an acceptable fit to the data as reflected by the chi-square value, $\chi^{2}(20)=246.8, p<$ 0.001 , and fit indices $(\mathrm{NFI}=0.73 ; \mathrm{CFI}=0.73 ; \mathrm{RMSEA}=0.18)$, which is not surprising given the comprehensiveness of our model (see also Bagozzi and Edwards, 1998). The model in Figure 9.2 was saturated and thus no meaningful fit statistics can be provided. We are not interested in model fit per se but rather in the significance of hypothesized paths and explained variance in our dependent variables. In the model for Navy personnel, our predictors explained 38.3 percent of total variance in scores on turnover intentions. For partners of Navy personnel, our predictors accounted for explained variances in the various attitudes toward the Navy ranging from 18 percent for identification with the Navy to 40.9 percent for satisfaction with the Navy.

\section{Test of hypotheses}

The results for Navy personnel are shown in Table 9.3. We found that work-to-family conflict was negatively associated with both satisfaction with the Navy $(\beta=-0.50 ; p<$ $0.001)$ and identification with the $\operatorname{Navy}(\beta=-0.22 ; p<0.001)$. In turn, satisfaction and identification with the Navy were negatively associated with turnover intentions ( $\beta=$ - 
0.34; $p<0.001$; and $\beta=-0.34 ; p<0.001$, respectively). In support of hypothesis 1 , mediation tests conducted using "RMediation" (Tofighi and MacKinnon, 2011) indicated that work-to-family conflict had significant indirect effects on turnover intentions among Navy personnel. The indirect effect estimate for work-to-family conflict through satisfaction with the Navy was 0.178, 95-percent CI [0.098, 0.273]. The indirect effect of work-family conflict through identification with the Navy was estimated at 0.08 with a 95-percent CI of [0.039, 0.127].

Table 9.3

Results from path analysis, Navy personnel

\begin{tabular}{|c|c|c|c|c|c|}
\hline Hypothesis & Path From & To & $\begin{array}{l}\text { Unstandardized } \\
\text { Path Coefficient }\end{array}$ & SE & $\begin{array}{l}\text { Critical } \\
\text { Ratio }\end{array}$ \\
\hline & Work-to-family conflict & Satisfaction with Navy & $-.44 * * *$ & .04 & -10.52 \\
\hline & Work-to-family conflict & Identification with Navy & $-.36 * * *$ & .09 & -4.13 \\
\hline & WFC x WF-specific team support & Satisfaction with Navy & $.15^{*}$ & .06 & 2.40 \\
\hline & WFC x WF-specific team support & Identification with Navy & $.28 *$ & .14 & 2.03 \\
\hline & Satisfaction with Navy & Turnover intentions & $-.41 * * *$ & .06 & -6.77 \\
\hline & Identification with Navy & Turnover intentions & $-.22 * * *$ & .03 & -6.84 \\
\hline & WF-specific team support & Family-to-work conflict & $-.16^{*}$ & .06 & -2.55 \\
\hline & Family-to-work conflict & Cognitive failures & $.50 * * *$ & .05 & 10.96 \\
\hline & Cognitive failures & Job satisfaction & $-.40 * * *$ & .04 & -10.25 \\
\hline & Job satisfaction & Turnover intentions & $-.28 * * *$ & .06 & -4.49 \\
\hline
\end{tabular}

Note. $\mathrm{WFC}=$ work-to-family conflict. $\mathrm{WF}=$ work-family.

$* p<.05 . * * * p<.001$ 
We found a significant interaction between work-to-family conflict and workfamily-specific team support in predicting satisfaction with the Navy $(\beta=0.12 ; p<$ 0.05; Figure 9.3) and identification with the Navy $(\beta=0.11 ; p<0.05$; Figure 9.4), supporting hypothesis 3. Moreover, we found that work-family-specific team support was associated with lower levels of family-to-work conflict $(\beta=-0.14 ; p<0.05)$, which supports hypothesis 4 .

Family-to-work conflict was positively associated with cognitive failures during deployment $(\beta=0.51 ; p<0.001)$, which in turn were associated with reduced job satisfaction $(\beta=-0.48 ; p<0.001)$. Finally, turnover intentions were higher among those who were less rather than more satisfied with their jobs $(\beta=-0.19 ; p<0.001)$. A test of double mediation using Hayes' PROCESS indicated that family-to-work conflict indirectly influenced turnover intentions via cognitive failures and job satisfaction. This indirect effect was estimated at 0.12 with a 95-percent CI of [0.08, 0.18]. Hence, also hypothesis 2 was supported.

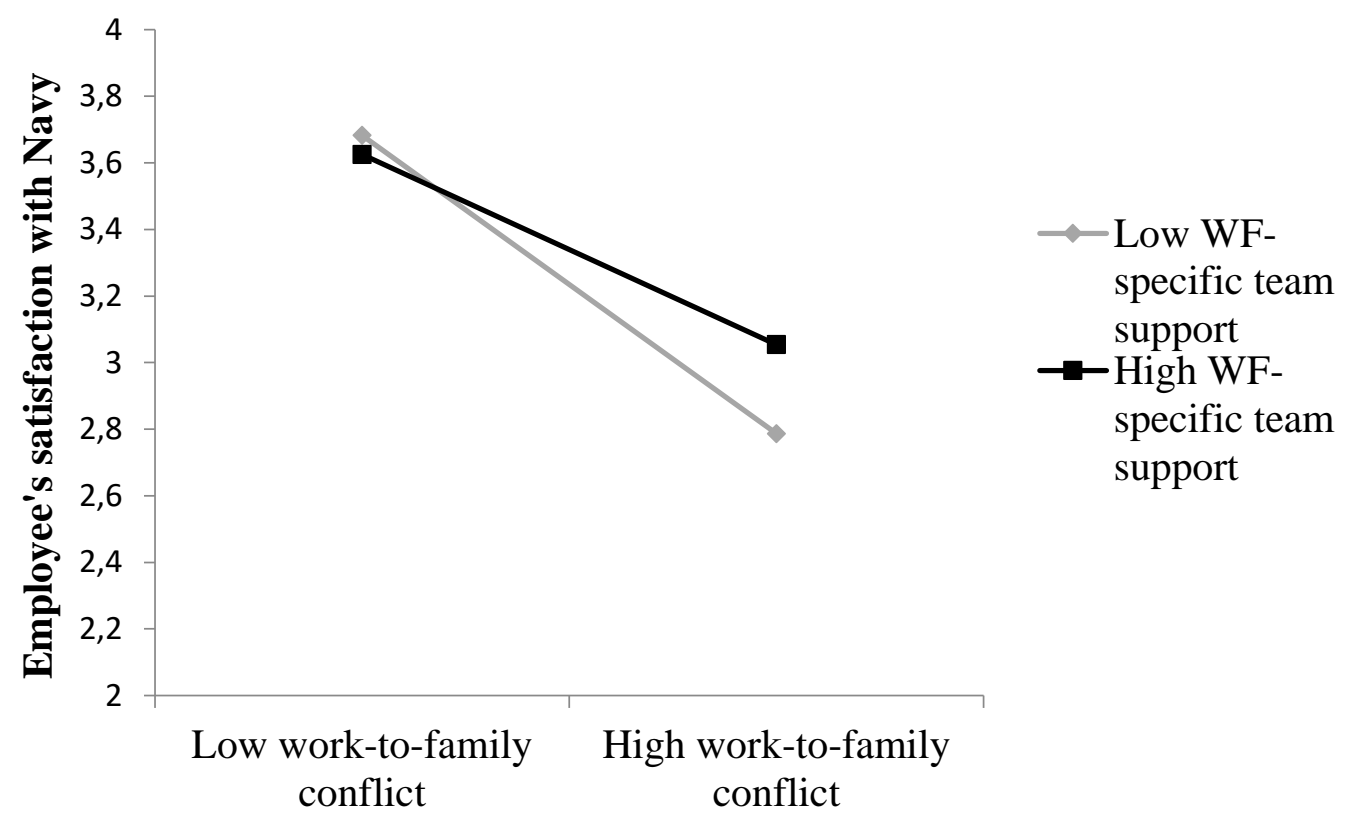

Figure 9.3

The interactive effect between work-to-family conflict and work-family-specific team support in predicting employees' satisfaction with the Navy 


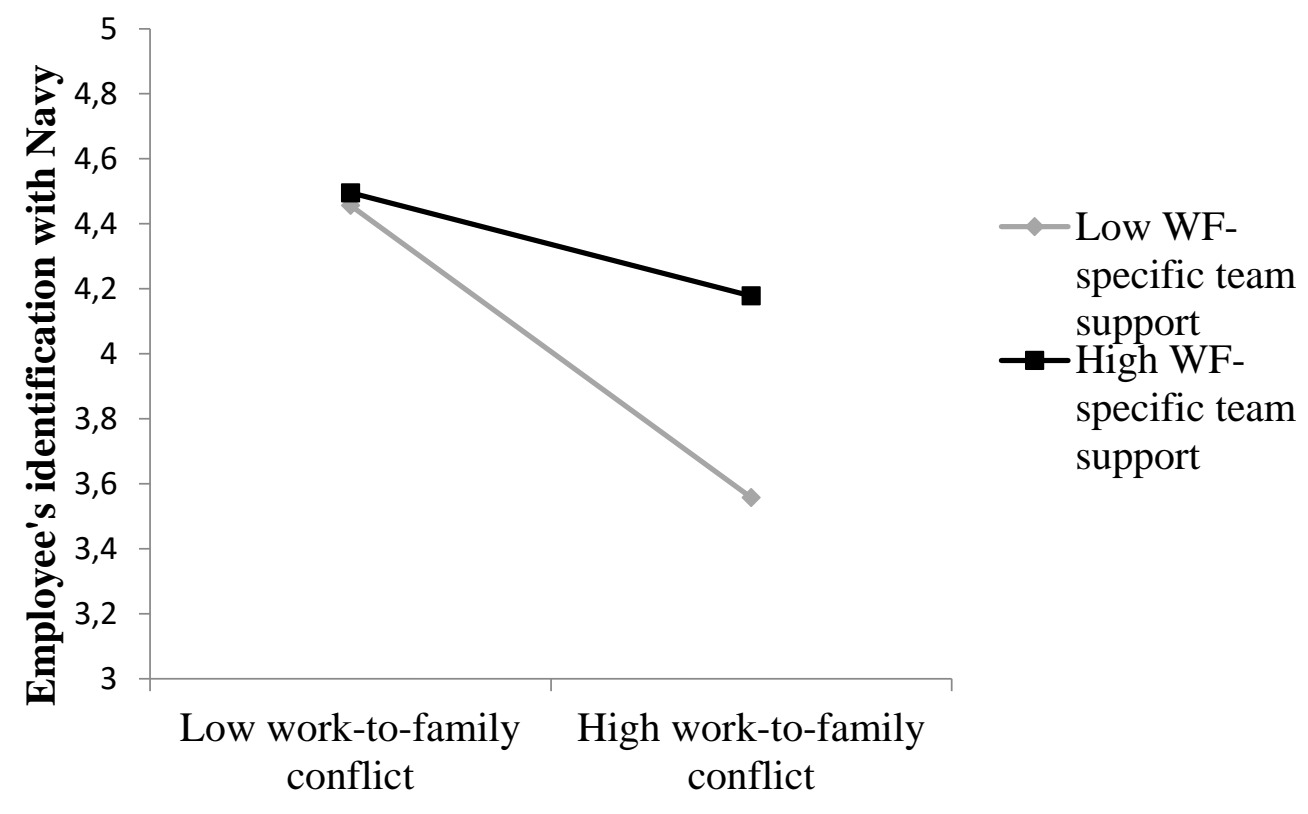

Figure 9.4

The interactive effect between work-to-family conflict and work-family-specific team support in predicting employees' identification with the Navy

Table 9.4 shows the results for partners of Navy personnel. Results indicated that partners' views of work-to-family conflict were negatively associated with satisfaction with the $\operatorname{Navy}(\beta=-0.44 ; p<0.001)$, identification with the Navy $(\beta=-0.22 ; p<0.01)$, and acceptance of separation $(\beta=-0.39 ; p<0.001)$. Moreover, opinions about the Navy as a career choice were more negative among those partners who perceived higher levels of interference with family life $(\beta=0.32 ; p<0.001)$. Thus, hypothesis 5 was fully supported. Support organized by the Navy was positively associated with all attitudes toward the Navy, namely satisfaction $(\beta=0.30 ; p<0.001)$, identification $(\beta=$ $0.22 ; p<0.05)$, acceptance of separation $(\beta=0.21 ; p<0.01)$, and opinion on the Navy as a career choice $(\beta=-0.23 ; p<.01)$, but did not reduce reactivity to work-to-family conflict in all instances. We found that the interaction between partners' views of workto-family conflict and support organized by the Navy was significant in predicting identification with the Navy ( $\beta=0.18 ; p<0.05$; Figure 9.5); in other words, support buffered the detrimental effect of work-to-family conflict perceptions on identification, as hypothesized. However, the interaction between partners' views of work-to-family conflict and support organized by the Navy was only marginally significant in 
predicting satisfaction with the Navy $(\beta=0.13 ; p=0.068)$ and support organized by the Navy did not buffer the relationships between work-to-family conflict on the one hand and acceptance $(\beta=0.08 ; p=0.298)$ and opinion $(\beta=-0.06 ; p=0.431)$ on the other. Thus, we found only partial support for hypothesis 6 .

\section{Table 9.4}

\section{Results from path analysis, partners}

\begin{tabular}{|c|c|c|c|c|c|}
\hline Hypothesis & Path From & To & $\begin{array}{l}\text { Unstandardized } \\
\text { Path Coefficient }\end{array}$ & SE & $\begin{array}{l}\text { Critical } \\
\text { Ratio }\end{array}$ \\
\hline & Work-to-family conflict & Satisfaction with Navy & $-.35 * * *$ & .06 & -6.04 \\
\hline & Work-to-family conflict & Identification with Navy & $-.39 * *$ & .15 & -2.61 \\
\hline & Work-to-family conflict & Opinion on Navy as career & $.36 * * *$ & .10 & 3.85 \\
\hline & Work-to-family conflict & Acceptance of separation & $-.35 * * *$ & .07 & -4.78 \\
\hline & WFC x support by Navy & Satisfaction with Navy & $.11 \dagger$ & .06 & 1.83 \\
\hline & WFC x support by Navy & Identification with Navy & $.34 *$ & .16 & 2.11 \\
\hline & WFC x support by Navy & Opinion on Navy as career & -.08 & .10 & -0.79 \\
\hline & WFC $\mathrm{x}$ support by Navy & Acceptance of separation & .08 & .08 & 1.04 \\
\hline
\end{tabular}

Note. WFC = work-to-family conflict.

$\dagger<.10 . * p<.05 . * * p<.01 . * * * p<.001$. 


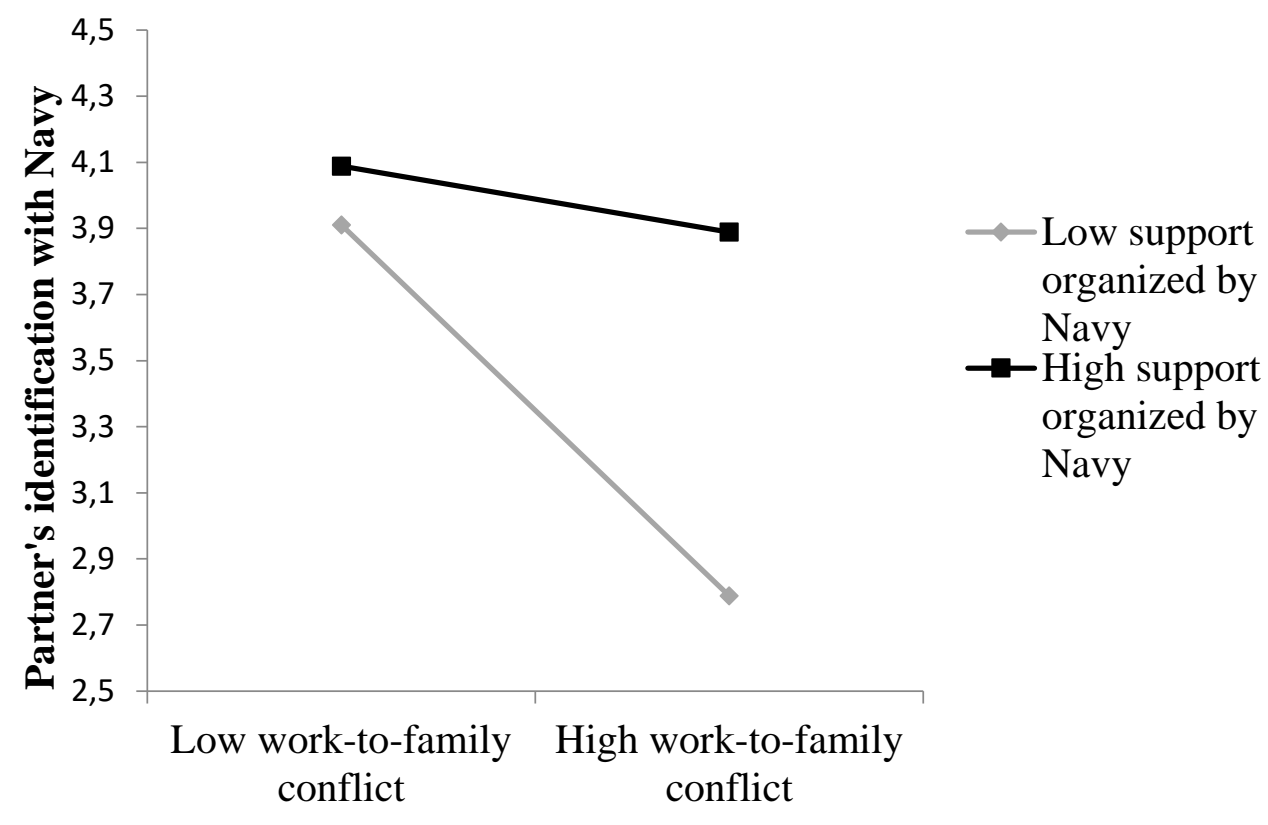

Figure 9.5

The interactive effect between work-to-family conflict and support organized by the Navy in predicting partners' identification with the Navy

\section{Discussion}

This study examined tensions in the military-employee-family triad and goes beyond prior research among military families in several important ways. While most research has primarily addressed the effects of military life and job demands on family dynamics and well-being, we have focused on organizational outcomes. Moreover, empirical work-family research in military contexts - in particular during operational conditions - is scarce and little is known about family members' attitudes toward the military. We have sampled the experiences of both service members and their partners during a deployment and have examined various attitudes toward the military. Our study demonstrates that work-family experiences during deployment are critical in determining attitudes toward the military and intentions to reenlist.

Both work-to-family conflict and family-to-work conflict increased the odds of turnover of military personnel, either because employees developed negative attitudes toward the Navy or because they could not function optimally at work and thus enjoyed the naval job less. Moreover, partners who felt that the naval job interfered with their 
home and family life were more likely to develop negative attitudes toward the Navy. Importantly, our findings also suggest that employers that are considered familyfriendly may face lower levels of turnover of service members. The benefits of support provided by team members and the organization are reciprocated by employees and their partners with positive attitudes toward the Navy, despite the experience that work interferes with family life, which may be inevitable in times of deployment. We conclude that perceived organizational work-family support is a powerful mechanism in the military-employee-family triad to improve attitudes and thus lower turnover intentions.

\section{Practical implications}

A key implication of our findings is that the military should be equally interested in the degree to which work interferes with family as in the degree to which family interferes with work, in order to prevent cognitive failures at work, negative attitudes, and ultimately high turnover, which all induce considerable organizational costs. Given that Navy personnel are away from their families during deployment, they are highly dependent on their team members on the ship. In order to reduce (reactivity to) workfamily tensions, it is critical that the team is able to establish a family-supportive climate. The military should ensure that Navy personnel feel psychologically safe to discuss any family matters and share concerns about their families on-board the ship. To this end, it is recommended that supervisors exhibit behaviors that are supportive of family, including role modeling behaviors that demonstrate how service members can successfully manage family separations, as supervisor support for family may be a key antecedent or subcomponent of family-supportive work climates (Hammer, Kossek, Yragui, Bodner, and Hanson, 2009).

Another implication that follows from our study is that any imbalance or tension in the work-family interface may result in changes to the status quo (i.e., intentions to leave the Navy) by which the service member attempts to restore the balance and attain a more positive outcome for the family. Thus, the experiences and attitudes of family members are an important factor for the military to pay attention to. To address the needs of stay-at-home families, the Navy can offer support during the absence of service members, organize home front groups, provide information on its website and 
social media, and facilitate communication between Navy personnel and their partners during sailing. The level of satisfaction with such initiatives is an important determinant of partners' attitudes toward the Navy, including the evaluation of whether the naval job is a good career choice for their partner.

\section{Limitations and future research}

Caution is warranted in drawing conclusions about causality in the relationships that we studied as our data stem from a cross-sectional research design. We suggest that future researchers test our model in a longitudinal fashion. Specifically, we recommend measurement of some of our constructs prior to, during, and after a job-induced family separation, to assess any fluctuations over the course of a deployment. This would offer a better understanding of the work-family experiences of both service members and their families. A second limitation of our study is that it does not shed light on what initiatives by the Navy or what behaviors of team members are seen as familysupportive. We recommend future researchers to use scales that assess specific support behaviors (see e.g., Hammer, Kossek, Yragui, Bodner, and Hanson, 2009).

Our argumentation on the benefits of social support did not take into account that individuals differ in their segmentation preferences (Chen, Powell, and Greenhaus, 2009); some try to keep work and family life separate most of the time, while others will talk as much as possible about their family and personal issues with their coworkers. Although we stick with our premise that the military should establish familysupportive team climates on their Navy ships, it should be noted that conversations about family matters may go against the segmentation preferences of some employees. Moreover, even for those who prefer to discuss family matters with colleagues, social support is associated with disadvantages, such as rumination (Boren, 2014), which may lead to cognitive failures and other forms of work impairment. In moving forward, it would be a valuable endeavor to gain further insights into the complexities of offering social support to military personnel and their partners. 


\section{References}

Adams, G. A., Jex, S. M., and Cunningham, C. J. L. (2006). Work-family conflict among military personnel. In C. A. Castro, A. B. Adler, and T. W. Britt (eds), Military Life: The Psychology of Serving in Peace and Combat. Volume 3: The Military Family. Westport, CT: Praeger.

Allen, T. D., French, K. A., Dumani, S., and Shockley, K. M. (2015). Meta-analysis of work-family conflict mean differences: does national context matter? Journal of Vocational Behavior, 90, 90-100.

Andres, M., Moelker, R., and Soeters, J. (2012). The work-family interface and turnover intentions over the course of project-oriented assignments abroad. International Journal of Project Management, 30, 752-759.

Bagozzi, R. P. and Edwards, J. R. (1998). A general approach for representing constructs in organizational research. Organizational Research Methods, 1, 4587.

Beauregard, T. A. (2006). Predicting interference between work and home: a comparison of dispositional and situational antecedents. Journal of Managerial Psychology, 21, 244-264.

Boren, J. P. (2014). The relationships between co-rumination, social support, stress, and burnout among working adults. Management Communication Quarterly, 28, $3-25$.

Bourg, C. and Segal, M. W. (1999). The impact of family supportive policies and practices on organizational commitment to the Army. Armed Forces \& Society, $25,633-652$.

Brayfield, A. H. and Rothe, H. F. (1951). An index of job satisfaction. Journal of Applied Psychology, 35, 307-311.

Broadbent, D. E., Cooper, P. F., FitzGerald, P., and Parkes, K. R. (1982). The cognitive failures questionnaire (CFQ) and its correlates. British Journal of Clinical Psychology, 21, 1-16.

Chen, Z., Powell, G. N., and Greenhaus, J. H. (2009). Work-to-family conflict, positive spillover, and boundary management: a person-environment fit approach. Journal of Vocational Behavior, 74, 82-93.

Cotton, J. L., and Tuttle, J. M. (1986). Employee turnover: a meta-analysis and review with implications for research. Academy of Management Review, 11, 55-70. 
De Angelis, K. and Segal, M. (2015). Transitions in the military and the family as greedy institutions: original concept and current applicability. In R. Moelker, M. Andres, G. Bowen, and P. Manigart (eds), Military Families and War in the 21st Century: Comparative Perspectives (pp. 22-42). London: Routledge.

Demerouti, E., Taris, T. W., and Bakker, A. B. (2007). Need for recovery, home-work interference and performance: is lack of concentration the link? Journal of Vocational Behavior, 71, 204-220.

Eisinga, R., Te Grotenhuis, M., and Pelzer, B. (2013). The reliability of a two-item scale: Pearson, Cronbach, or Spearman-Brown? International Journal of Public Health, 58, 637-642.

Geurts, S. A. E., Taris, T. W., Kompier, M. A. J., Dikkers, J. S. E., Van Hooff, M. L. M., and Kinnunen, U. M. (2005). Work-home interaction from a work psychological perspective: development and validation of a new questionnaire, the SWING. Work \& Stress: An International Journal of Work, Health, \& Organisations, 19, 319-339.

Greenhaus, J. H. and Powell, G. N. (2012). The family-relatedness of work decisions: A framework and agenda for theory and research. Journal of Vocational Behavior, 80, 246-255.

Griffeth, R. W., Hom, P. W., and Gaertner, S. (2000). A meta-analysis of antecedents and correlates of employee turnover: update, moderator tests, and research implications for the next millennium. Journal of Management, 26, 463-488.

Hammer, L., Kossek, E. E., Yragui, N., Bodner, T., and Hanson, G. (2009). Development and validation of a multidimensional scale of family-supportive supervisor behaviors (FSSB). Journal of Management, 35, 837-856.

Huffman, A. H., Casper, W. J., and Payne, S. C. (2013). How does spouse career support relate to employee turnover? Work interfering with family and job satisfaction as mediators. Journal of Organizational Behavior, 35, 194-212.

Kelley, M. L., Hock, E., Bonney, J. F., Jarvis, M. S., Smith, K. M., and Gaffney, M. A. (2001). Navy mothers experiencing and not experiencing deployment: Reasons for staying in or leaving the military. Military Psychology, 13, 55-71.

Kossek, E. E., Colquitt, J. A., and Noe, R. A. (2001). Caregiving decisions, wellbeing, and performance: the effects of place and provider as a function of dependent type and work-family climates. Academy of Management Journal, 44, $29-44$. 
Kossek, E. E., Pichler, S., Bodner, T., and Hammer, L. B. (2011). Workplace social support and work-family conflict: Aa meta-analysis clarifying the influence of general and work-family-specific supervisor and organizational support. Personnel Psychology, 64, 289-313.

Lapierre, L. M., Hammer, L. B., Truxillo, D. M., and Murphy, L. A. (2012). Family interference with work and workplace cognitive failure: the mitigating role of recovery experiences. Journal of Vocational Behavior, 81, 227-235.

Lent, R. W. and Brown, S. D. (2006). Integrating person and situation perspectives on work satisfaction: a social-cognitive view. Journal of Vocational Behavior, 69, 236-247.

Netemeyer, R. G., Boles, J. S., and McMurrian, R. (1996). Development and validation of work-family conflict and family-work conflict scales. Journal of Applied Psychology, 81, 400-410.

Peeters, M. C. W., Ten Brummelhuis, L. L., and Van Steenbergen, E. F. (2013). Consequences of combining work and family roles: a closer look at cross-domain versus within-domain relations. In J. G. Grzywacz and E. Demerouti (eds), New Frontiers in Work and Family Research (pp. 93-109). East Sussex: Psychology Press.

Powell, G. N., Francesco, A. M., and Ling, Y. (2009). Toward cultural-sensitive theories of the work-family interface. Journal of Organizational Behavior, 30, $597-616$.

Premeaux, S. F., Adkins, C. L., and Mossholder, K. W. (2007). Balancing work and family: a field study of multi-dimensional, multi-role work-family conflict. Journal of Organizational Behavior, 28, 705-727.

Segal, M. W. (1986). The military and the family as greedy institutions. Armed Forces \& Society, 13, 9-38.

Shamir, B. and Kark, R. (2004). A single-item graphic scale for the measurement of organizational identification. Journal of Occupational and Organizational Psychology, 77, 115-123.

Shanock, L. R. and Eisenberger, R. (2006). When supervisors feel supported: relationships with subordinates' perceived supervisor support, perceived organizational support, and performance. Journal of Applied Psychology, 91, $689-695$. 
Shockley, K. M. and Singla, N. (2011). Reconsidering work-family interactions and satisfaction: a meta-analysis. Journal of Management, 37, 861-886.

Tett, R. P. and Meyer, J. P. (1993). Job satisfaction, organizational commitment, turnover intention, and turnover: path analyses based on meta-analytic findings. Personnel Psychology, 46, 259-293.

Tofighi, D. and MacKinnon, D. P. (2011). RMediation: an R package for mediation analysis confidence intervals. Behavior Research Methods, 43, 692-700.

Van Dick, R., Christ, O., Stellmacher, J., Wagner, U., Ahlswede, O., Grubba, C., . . . Tissington, P. A. (2004). Should I stay or should I go? Explaining turnover intentions with organizational identification and job satisfaction. British Journal of Management, 15, 351-360.

Wallace, J. C. and Chen, G. (2005). Development and validation of a work-specific measure of cognitive failure: implications for occupational safety. Journal of Occupational and Organizational Psychology, 78, 615-632. 